\title{
Effect of Rajyoga in the Auditory reaction time of Attention Deficit Hyperactivity Disorder
}

\section{Anshuman Naik ${ }^{* 1}$, Shashikala Patel ${ }^{2}$, Biswas D.A ${ }^{3}$.}

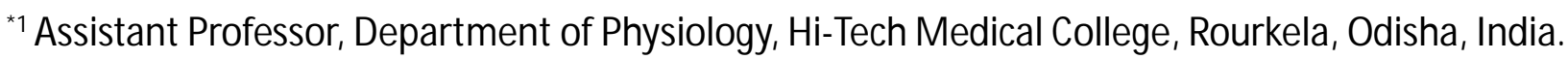

${ }^{2}$ Assistant Professor, Department of Anatomy, Hi-Tech M edical College, Rourkela, Odisha, India.

${ }^{3}$ Vice Dean, JNM C, Wardha, M ahrashtra, India.

\section{ABSTRACT}

Introduction: Attention Deficit Hyperactivity Disorder is characterized by inattentiveness. Pharmacological intervention for Attention Deficit Hyperactivity Disorder, although effective, is far from satisfactory because of incomplete benefit, treatment failures and troublesonie side effects. Therefore, alternative and complementary treatments are needed to optimize therapeutic effects. Rajyoga meditation of Brahmakumaris subsumes within itself the fundamentals of all methods of yoga and confers the achievement of all of them naturally and easily using one very simple method which anyone can learn.

Objective: This study was an attempt to evaluate the role of Rajyoga meditation on Auditory Reaction Time of ADHD cases.

Materials and M ethods: 42 ADHD cases were recruited. Auditory reaction time were recorded before and after intervention i.e. Rajyoga for three months. Student t test was used to evaluate the recorded data.

Results: Mean auditory mean reaction time decreased from 330.09 \pm 113.46 milliseconds to $280.16 \pm 108.46$ milliseconds after 12 weeks of Rajyoga Meditation.

Conclusion: Rajyoga is a cheap and cost effective way to increase attention span in ADHD cases.

KEY WORDS: ADHD, Rajyoga, Reaction time, Yoga, M editation,

Address for correspondence: Dr.Anshuman Naik,Assist.Professor,Department of Physiology, Hi-Tech Medical College, Rourkela-769004, Odisha, India. Mobile No.: +919178678123

E-M ail: anshumandoctor@gmail.com

\begin{tabular}{|c|c|c|}
\hline \multicolumn{3}{|c|}{ Online Access and Article Informtaion } \\
\hline \multirow{2}{*}{$\begin{array}{c}\text { Quick Response code } \\
\text { Dol: } 10.16965 / \text { ijims.2016.121 }\end{array}$} & \multicolumn{2}{|c|}{$\begin{array}{l}\text { International Journal of Integrative Medical Sciences } \\
\text { www.imedsciences.com }\end{array}$} \\
\hline & $\begin{array}{l}\text { Received: 18-05-2016 } \\
\text { Reviewed: 18-05-2016 }\end{array}$ & $\begin{array}{l}\text { Accepted: 14-06-2016 } \\
\text { Published: 30-06-2016 }\end{array}$ \\
\hline Source of Funding: Self & \multicolumn{2}{|c|}{ Conflicts of interest: None } \\
\hline
\end{tabular}

\section{BACKGROUND}

Attention Deficit Hyperactivity Disorder "a serious public health problem," [1] with prevalence of $5-12 \%$ of children worldwide [2] and 10 to $20 \%$ in India [3] is a developmental disability [4] and neurobehavioral disorder [5] characterised by inattentiveness, hyperactivity and impulsivity [6]. Attention is most likely conscious and unconscious process complete with underlying neurophysiological mechanisms, which we are into.
Pharmacological intervention for Attention Deficit Hyperactivity Disorder, although effective, is far from satisfactory because of incomplete benefit, treatment failures and troublesonie side effects. Even when combined with behaviour modification, cognitive behaviour therapy, and/or parent training, behaviour is rarely completely normalized.Therefore, alternative and complementary treatments are needed to optimize therapeutic effects [7].

Rajyoga meditation of Brahmakumaris 
subsumes within itself the fundamentals of all methods of yoga and confers the achievement of all of them naturally and easily using one very simple method which anyone can learn [8].

Previous studies reported that ADHD is associated with Slower reaction times or attention span [9], Impaired time sense [10], Response inhibition impairment [11].

This study was an attempt to evaluate the role of autogenic relaxation therapy (Rajyoga meditation) on Visual and Auditory Reaction Time of ADHD

\section{MATERIALS AND METHODS}

42 ADHD cases were recruited. Ages of the ADHD children range from 8 to 15 years. Mean age of the children was $11.24 \pm 1.82$ years. Written informed consent/permission was obtained from parents/guardians/principal of the school/class teacher as the children were minors. IEC approval obtained. Auditory reaction time was recorded before and after intervention i.e.Rajyoga for three months.

Apparatus used in this study was the portable simple audiovisual timer or 'Response Analyzer' by INCO "Yantra Shilpa" Systems, Pune, which had a display accuracy of 0.001 second. It consisted of three display lights (Red, Green and Yellow) towards which the subject had to attentively look and a button which shifts the stimulus from a visual to an auditory signal. There was a digital display monitor which indicated reaction time in milliseconds.

The reading was taken in a relatively quiet and properly illuminated room in morning hours. The intensity of the stimulus was same for all the subjects. To avoid the effect of lateralised stimulus, visual and auditory signals were given from the front of the subject, who was instructed to use his/her, dominant hand while responding to the signal. Three readings of each stimulus were noted and the lowest was taken as the Reaction Time.

The subject was asked to sit on a chair comfortably in such a way that the display was not made visible to the subject to prevent bias on part of the subject. All the subjects were thoroughly acquainted with apparatus. Three practice trials were given every time before taking the reading for 15 to 20 minutes. The auditory stimulus was presented in the form of beep at random. The subject was asked to press a particular button in the panel of the unit with the index finger of dominant hand. The counting in milliseconds continued till the subject pressed a button which he/she heard the stimulus, as the case may be. At the press of the button, the programme stopped counting and the Reaction Time was shown on display.

Subjects were taught Rajyoga Meditation by Rajyoga teachers. Relaxation was achieved by giving training in Rajyoga M editation according to teachings of Rajyoga Education and Research Foundation to subjects by the experts from Brahma Kumaris Spiritual University. Meditation training was given with the help of pictures, diagrams and audio CD.A total of 8 lessons each of 45 minutes were given, of which last 20 minutes were devoted to a guided commentary.Subjects were instructed to practice Rajyoga at starting of school for 10minutes per day for 3 months.

Statistical Package for Social Sciences (SPSS) version 17.0 was used for statistical analysis of the data. M ean and Standard Deviation ( \pm SD) of all observation were calculated and comparisons were done between values of pre and post data (M ean and $\pm S D$ ) of 12 week Rajyoga M editation applying paired Student's " $t$ " test. Statistical significance was assigned at $\mathrm{P}<0.05$ and $P \varangle 0.001$ was considered to be highly significant.

\section{RESULTS}

In Table-1 shows M ean auditory mean reaction time decreased significantly from $330.09 \pm 113.46$ milliseconds to280.16 \pm 108.46 milliseconds $(t=12.71, p \measuredangle 0.001)$ after 12 weeks of Rajyoga Meditation.

Table1: Comparison of Auditory Reaction Time before and after 12 weeks of Rajyoga.

\section{Descriptive Statistics}

\begin{tabular}{|c|c|c|c|c|}
\hline ART & Mean & N & $\begin{array}{c}\text { Std. } \\
\text { Deviation }\end{array}$ & $\begin{array}{c}\text { Std. Error } \\
\text { Mean }\end{array}$ \\
\hline $\begin{array}{c}\text { Before } \\
\text { Rajyoga }\end{array}$ & 330.09 & 42 & 113.46 & 17.5 \\
\hline $\begin{array}{c}\text { After } \\
\text { Rajyoga }\end{array}$ & 280.16 & 42 & 108.46 & 16.73 \\
\hline
\end{tabular}




\section{Students paired $\mathbf{t}$ test}

\begin{tabular}{|c|c|c|c|c|c|c|c|c|}
\hline & \multicolumn{5}{|c|}{ Paired Differences } & & & \\
\cline { 2 - 5 } ART & Mean & $\begin{array}{c}\text { Std. } \\
\text { Deviation }\end{array}$ & $\begin{array}{c}\text { Std. Error } \\
\text { Mean }\end{array}$ & $\begin{array}{c}\text { 95\% Confidence } \\
\text { Interval of the } \\
\text { Difference }\end{array}$ & $\mathrm{t}$ & $\mathrm{df}$ & $\mathrm{p}$-value \\
\cline { 4 - 6 } & & Lower & Upper & & \\
\hline $\begin{array}{c}\text { Before-After } \\
\text { Rajyoga }\end{array}$ & 49.92 & 25.44 & 3.92 & 41.95 & 57.85 & 12.71 & 41 & $p<0.0015$ \\
\hline
\end{tabular}

*S=Significant

\section{DISCUSSION}

Decrease in Reaction time indicates an improved sensory-motor performance and enhanced processing ability at the primary thalamocortical level of central nervous system. This may be due to greater arousal, faster rate of information processing, improved concentration and/or an ability to ignore extraneous stimuli. Yoga namely Rajyoga M editation results in decreased mental fatigability and increase in performance quotient.

Similar findings were reported by Udupa KN et al [12], Malathi A

et al [13], M adanmohan et al [14], Borkar AS et al [15] and Madanmohan et al [16] where they reported yoga produces a significant decrease in visual and auditory reaction time.

In 2009 N.V.V.S. Narayana [17] observed significant $(p<0.01)$ effect of yoga on visual reaction time. In 2010 Biswas D. A. [18] observed significant $(p \varangle 0.01)$ declined in visual reaction time and significant $(p \varangle 0.05$ change in auditory reaction time after 4 weeks of Yoga. Visual reaction time declined significantly $(p<0.01)$ after 4 weeks of Rajyoga Meditation in healthy volunteers.

Reaction time is psychomotor test[19]. Reaction time is the time interval between the application of a stimulus and the appearance of appropriate voluntary response by a subject. It involves stimulus processing, decision making and response programming [20].

Processing speed and motor speed appear to be dependent on cerebral dopaminergic systems [20] which are imbalance in ADHD and meditation increases endogenous levels of dopamine [21].

There are basically 3 stages of information processing-input (information processed by auditory or visual senses), integration (interpreted, categorized place in sequence or related to previous learning) and output. (Language output or muscle activity) Deficient in any area of information processing results in discrepancy between the individual's potential ability and academic performance [22].ADHD is characterised by response inhibition [11].

Lutz $A$ et al [23] observed that 3 months of meditation training reduced variability in attentional processing of target tones, as indicated by both enhanced theta-band phase consistency of oscillatory neural responses over anterior brain areas and reduced reaction time variability.

Some of the transient changes in brain activity due to meditation include bursts of oscillations and increases in global frontocentral coherences, especially in the lower frequency range. (i.e. alpha and the theta) M editators have been found to self-induce gamma-band oscillations and phase synchronization during meditation, especially in the frontoparietal areas, which signifies an attentive brain. These changes in brain activity and cognitive processes appear beneficial, thus improving overall cognitive functioning [24].

\section{CONCLUSION}

Rajyoga is a cheap and cost effective way to increase attention span in ADHD cases.

\section{REFERENCES}

[1]. Frances E.Kuo, Andrea Faber Taylor. A potential natural treatment for attention-deficit/ hyperactivity disorder: evidence from a national study. Am J Public Health 2004; 94(9):1580-1586.

[2]. Lacramioara Spetie, Eugene L.Arnold. Attentiondeficit/ hyperactivity disorder. In: Andres Martin, Fred R Volkmar (eds.) Lewis's child and adolescent psychiatry a comprehensive text book. 4th edi. Philadelphia, Lippincott Williams \& Wilkins; 2007.p 430-454.

[3]. Malhi Prahbhjot, Singhi Pratibha. Spectrum of attention deficit hyperactivity disorders in children among referrals to psychology services. Indian Pediatrics 2000; 37:1256-1260.

[4]. Kelly A.Brown,Dilip R.Patel. Complementary and alternative medicine in developmental disabilities. Indian J Pediatr 2005; 72(11):949-952.

[5]. Malhi Prahbhjot, Singhi Pratibha, Sindhu Manjit. Impact of parent and teacher concordance on diagnosing attention deficit hyperactivity disorder and its sub-types. Indian J Pediatr 2008; 75(3):223228. 
[6]. Michael B. First, Allan Tasman (eds.) Childhood disorders: attention-deficit and disruptive behavior disorders, In: DSM-IV-TR TM Mental disorders diagnosis, etiology \& treatment. England, Wiley West Sussex; 2004.p 158-186.

[7]. Pauline S. Jensen, Dianna T. Kenny. The effects of yoga on the attention and behavior of boys with attention-deficit/hyperactivity disorder (ADHD). J. of Att.Dis.2004; 7(4): 205-216.

[8]. Robert Shubow, Hansa Raval, Nirmala Kajaria, Harold Streitfeld, Heidi Fittkau, Prem M asand (eds.) Easy Rajyoga: basic technique, In: Positive Health. Delhi, Prajapita brahma kumaris ishwariya vishwa vidyalaya; 1986.p70-82.

[9]. Singhal Harish Kumar, Neetu, Kumar Abhimanyu, Rai Moti. Ayurvedic approach for improving reaction time of attention deficit hyperactivity disorder affected children. AYU 2010; 31(3): 338342.

[10]. Roberte Hales, Stuarc C. Yudofsky, Johhn A. Talbott (eds.) Disorders usually first diagnosed in infancy, childhood or adolescence. In: Textbook of Psychiatry. $3^{\text {rd }}$ edi. Washington, The American psychiatric press; 1999. p827-855.

[11].Kurt P. Schulz, Jin Fan, Cheuk Y. Tang, Jeffrey $H$. Newcorn, M onte S. Buchsbaum, Angeles M. Cheung, et al. Response inhibition in adolescents diagnosed with attention deficit hyperactivity disorder during childhood: an event related fMRI study. Am. J. Psychiatry 2004; 161: 1650-1657.

[12]. Udupa KN, Singh RH. The scientific basis of yoga. JAM A 1972; 220: 1365.

[13]. M alathi A, Parulkar VG. Effect of yogasanas on the visual and auditory reaction time. Ind. J. Physiol. Pharmacol. 1989; 33(1): 110-112.

[14].Madanmohan, Thombre DP, Balakumar B, Naminaryanan TK, Thakur S, Krishnamurthy $\mathrm{N}$, et al. Effect of yoga training on reaction time, respiratory endurance and muscle strength. Ind. J. Physiol. Pharmacol. 1992; 36(4): 229-233.
[15]. Borkar AS, Pednekar JR. Effect of pranayama on visual and auditory reaction time. Ind. J. Physiol. Pharmacol. 2003; 47(2): 229-230.

[16]. Madanmohan, Udupa KN, Bhavanani A, Jatiya L. Effect of yoga training on handgrip, respiratory pressures and pulmonary function. Ind. J. Physiol. Pharmacol. 2003; 47(4): 387-392.

[17]. N.V.V.S. Narayana. The effect of yoga on visual reaction time. Indian Journal of Social Science Researches 2009; 6(2): 63-70.

[18]. Biswas D.A. Effects of short term yoga training on pulmonary $\&$ reaction time in students of rural medical institution. JIM SA 2010; 23(2): 71-72.

[19]. AH Shah, SV Joshi, PP M ehrotra, Naina Potdar, HL Dhar. Effect of saral meditation on intelligence, performance and cardiopulmonary functions. Indian J. Med. Sci. 2001; 55(11): 604-8.

[20]. Asmita S. Nene, Pushpa A. Pazare. A study of auditory reaction time in different phases of the normal menstrual cycle. Ind. J. Physiol. Pharmacol. 2010; 54(4): 386-390.

[21]. Linda J. Harrison, Ramesh Manocha, Katya Rubia. Sahaja yoga meditation as a family treatment programme for children with attention deficithyperactivity disorder. Clinical Child Psychology and Psychiatry 2004; 9(4): 479-497.

[22]. Farah Khaliq, Kaushal Kumar Alam, Neelam Vaney, T. B. Singh. Sensory, cognitive and motor assessment of children with poor academic performance: an auditory evoked potential study. Ind. J. Physiol. Pharmacol. 2010;54(3):255-264.

[23]. Lutz A, Slagter HA, Rawlings NB, Francis AD, Greischar LL, Davidson RJ. Mental training enhances attentional stability: neural and behavioural evidence. J. Neurosci. 2009;29(42) :13418-27.

[24]. Baijal Shruti, Gupta Rashmi. Meditation based training: a possible intervention for attention deficit hyperactivity disorder?. Psychiatry (Edgmont). 2008;5(4):48-55.

\section{How to cite this article:}

Anshuman Naik, Shashikala Patel, Biswas D.A. Effect of Rajyoga in the Auditory reaction time of Attention Deficit Hyperactivity Disorder. Int J Intg Med Sci 2016;3(6):296-299. DOI: 10.16965/ijims.2016.121 